\title{
Türkiye'de Demiryolu İstasyonlarının Değerlendirilmesi İçin Analitik Hiyerarşi Süreci Uygulaması
}

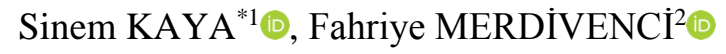 \\ ${ }^{1}$ TCDD Taşımacılık A.Ş. Yük Dai. Başk., Uluslararası Taş. Şubesi, 06560, Ankara, Türkiye \\ ${ }^{2}$ Akdeniz Üniv., Uyg. Bil. Fak., Uluslararası Tic. ve Loj. Bölümü, 07070, Antalya, Türkiye \\ *kayasinem@hotmail.com.tr
}

(Alınış/Received: 21.01.2020*, Kabul/Accepted: 06.07.2020, Yayımlama/Published: 31.07.2020)

Öz: Taşımacılık sektöründe önemli bir paya sahip olan demiryolu taşımacıllğı, rekabet üstünlüğü göstermek adına fark yaratacak donanıma sahip olmak zorundadır. Özellikle seyahat edenlerin demiryolu ile yolculuk yapma tercihini arttırmak için, demiryolu istasyonlarının sunduğu hizmetlerin kalitesi ve çeşitliliği önemli etkenler arasındadır. Bu çalışma yolcu taşımacıllı̆ında istasyonların sunduğu hizmetleri değerlendirmek amacıyla yapılmış bir araştırmadır. Türkiye demiryolu istasyonlarının birbirlerine göre sundukları hizmet kalemlerini değerlendirmek için çok kriterli karar verme yöntemlerinden Analitik Hiyerarşi Süreci (AHS) kullanılmıştır. En sık kullanılan 5 demiryolu istasyonu (Ankara, İstanbul, Eskişehir, Kütahya ve Kocaeli) ile 10 hizmet kriteri (Temizlik, Güvenlik, Bekleme Salonu, Gişe Hizmeti, Perona Ulaşım Kolaylığı, Yeme-İçme Hizmeti, Taşıyıcılar, Proaktiflik, Bağlantı Olanakları, Merkeze Yakınlık) değerlendirilerek ağırlık değerleri AHS yöntemi ile belirlenmiş ve alternatiflerin sıralaması yapılmıştır. Yapılan araştırma sonucunda "Güvenlik ve Proaktiflik" 'istasyon performansını etkileyen en önemli kriterler olup, hizmet düzeyi en yüksek istasyon ise "Ankara" olarak değerlendirilmiştir.

Anahtar kelimeler: Taşımacılık, Demiryolu Taşımacılığı, Analitik Hiyerarşi Süreci

\section{Application of Analytic Hierarchy Process for Evaluation of Railway Stations In Turkey}

\begin{abstract}
Rail transport, which has a significant share in the transport sector, has to have the equipment to make a difference in order to show competitive advantage. The quality and variety of services offered by railway stations are among the key factors, especially in order to increase the choice of travellers to travel by rail. This study was conducted to evaluate the services offered by stations in passenger transport. Analytical Hierarchy Process (AHP), one of the multi-criteria decision making methods, was used to evaluate the service items offered by Turkish railway stations relative to each other. The 5 most frequently used railway stations (Ankara, İstanbul, Eskişehir, Kütahya and Kocaeli) and 10 service criteria (Cleaning, Security, Waiting Room, Box Office Service, Ease of Access to the Platform, Food and Drink Service, Carriers, Proactive, Connectivity Facilities, Proximity to the Center) were evaluated and weight values were determined with AHP method and alternatives were sorted. As a result of the research, "Safety and Proactive" are the most important criteria affecting the performance of the station, and the station with the highest level of service was evaluated as "Ankara".
\end{abstract}

Keywords: Transportation, Railway Transportation, Analytical Hierarchy Process

\section{Giriş}

Taşımacılık, ihtiyaçların ortaya çıkması ile canlı veya cansız mal ve varlıkların ya da bilgi ve belgelerin bir yerden başka bir yere talepler dâhilinde yer değiştirmesi faaliyetidir [1]. Taşımacılık dünya genelinde günden güne gelişim gösteren ve önem kazanan bir sektör haline gelmiştir. Taşımacılık faaliyetinin geliştirilmesi ile beraber sınırlar genişlemiş ve farklı ülkelere, bölgelere ve milletlere ulaşabilme olanağı sağlanmıştır. 


\section{Demiryolu Mühendisliği}

Türkiye Devlet Demiryolları, devlet kontrolünde işletilen, ekonomik büyüme üzerinde olumlu etkisi olan sektörlerden birisi olarak, taşımacılığın önemli bir parçası durumundadır. Altyap1 yatırımlarının arttırılması, hatların yenilenerek geliştirilmesi, sinyalizasyon ve elektrifikasyon çalışmaları ile daha akıllı sisteme sahip istasyonlarla hizmet vermek, demiryolu taşımacılığını olumlu yönde etkileyen faktörlerdir. İstasyonlar yolcuların seyahat etmek için iniş-biniş yaptıkları ve malların yüklenip-boşaltıldığı önemli noktalardır. Her şeyden önce istasyonların gelişimi yük ve yolcu taşımacılığında demiryolunun kârı için çok önemlidir [2]. İstasyonun hizmet düzeyini belirleyen, hizmet verdiği alanda güvenlik, temizlik, bekleme salonu, istasyonun merkeze yakın olması vb. gibi çeşitli özelliklere sahip olmasıyla belirlenmektedir. Hizmet kalemlerinin çeşitliliği istasyonun cazibesini arttırarak yolcu potansiyelini etkilemektedir [3]. Buna örnek olarak, Haydarpaşa ve Sirkeci istasyonları günümüzde de hala güzelliklerini koruyan, sundukları hizmetler ile dikkat çeken mimari yapılar arasındadır [4].

$\mathrm{Bu}$ çalışmada, demiryolu ile yolcu taşımacılı̆̆ında, istasyonlara yapılan yatırımların ve yolculara sunulan hizmet kapsamında, güvenlik, temizlik, bekleme salonu vs. gibi istasyon hizmetleri ile her istasyonun hizmet düzeyinin belirlenmesi amaçlanmıştır. Türkiye'de hizmet veren istasyonların sahip oldukları imkân ve olanakların, istasyondan istasyona farklılık göstermesinin yolcu taşımacıllı̆ına olan etkisi ölçülmek istenmektedir. İstasyonda verilen hizmet ve kalitenin değeri hangi istasyonu daha ön plana çıkardığını görmek ve bu yönde bütün istasyonların akıllı sistemlerle geliştirilmesi ve standartlaştırılmasının taşımacılığa olan etkisi ön plana çıkarılması amaçlanmaktadır.

Bu amaçla, Türkiye'de sık kullanılan demiryolu istasyonlarının hizmet değerlendirmesi yapmak amacıyla aşağıdaki bölümlerde uygulanacak olan, çok kriterli karar verme yöntemlerinden Analitik Hiyerarşi Süreci kullanılacaktır. Türkiye'de sık kullanılan 5 demiryolu istasyonu (Ankara, İstanbul, Eskişehir, Kütahya ve Kocaeli) belirlenerek, 10 hizmet kriteri (temizlik, güvenlik, bekleme salonu, gişe hizmeti, perona ulaşım kolaylığı, yeme-içme hizmeti, taşıyıcılar, proaktiflik, bağlantı olanakları, merkeze yakınlık) ile değerlendirme yapılacaktır. Kriterlerin ve alternatiflerin ağırlık puanları AHS ile belirlenerek, hizmet düzeyi yüksek olan istasyon siralamas1 elde edilecektir.

\section{Materyal ve Metot}

Türkiye'de demiryolu istasyon hizmetlerini değerlendirmek için, çok kriterli karar verme yöntemlerinden Analitik Hiyerarşi Süreci kullanılmıştır. Uzman görüşleri ve literatür taraması ile istasyon hizmetleri için 12 kriter belirlenmiş, en fazla kullanılan 5 istasyon üzerinde değerlendirme yapılmıştır. Öncelikle 5 alternatif istasyon ve 10 değerlendirme kriterinin ağırlıkları AHS yöntemi ile hesaplanmış ve sonrasında öncelik sıralaması yapılmıştır.

Analitik Hiyerarşi Süreci (Analytic Hierarcy Process) yöntemi "Thomas L. Saaty" ile 1970 yılında birden fazla amaçlı karar verme sorunlarına çözüm getirmek amacıyla oluşturulmuş her bir nitel veya nicel kriterin birbirine göre önem derecelerini belirlemek için karar vericilere gereksinim duyup, daha sonra her bir kriter kullanılarak, karar alternatiflerini çoklu kriterler altında değerlendirme yapmayı sağlayan bir yöntemdir. Bu amaçla geliştirilen yöntemlerin sayısı oldukça fazladır. Dolayısıyla çok kriterli karar verme yöntemleri, karar vericiye araştırmalar sonucu elde ettiği bilgileri en uygun şekilde değerlendirme olanağı sunarken, amaçlarını ya da hedeflerini gerçekleştirebilmesi için belirlediği seçenekleri farklı ölçütlere göre değerlendirebilmesine de olanak sağlar [5].

Literatürden elde edilen, çok kriterli karar verme yöntemleri kullanılarak demiryolu ile ilgili yapılan çalışma örnekleri Tablo 1'de özetlenmiştir. 


\section{Demiryolu Mühendisliği}

Tablo 1. Çok kriterli karar verme yöntemleri ile yapılan demiryolu çalışmaları

\begin{tabular}{cll}
\hline Kaynak & \multicolumn{1}{c}{ Yöntem } & \multicolumn{1}{c}{ Problem } \\
\hline$[2]$ & AHP-MABAC & $\begin{array}{l}\text { Hindistan demiryolu istasyonlarının performanslarının } \\
\text { değerlendirilmesi }\end{array}$ \\
{$[6]$} & AHP(Analytic & İstanbul'da demiryolu transit ağlarının değerlendirilmesi \\
{$[7]$} & Hierarcy Process) & Kirgızistan da demiryolu güzergâhlarını planlama \\
{$[8]$} & AHP & Demiryolu istasyonu için konum seçimi \\
{$[9]$} & ANP & Metro hattı merkezi yeri seçimi \\
{$[10]$} & TOPSIS & Pekin Güney demiryolu istasyonunda büyük nakliye terminalleri \\
{$[11]$} & TOPSIS, VIKOR & İltisak hattı bağlantı projelerinin değerlendirilmesi \\
{$[12]$} & AHP & Kirıkkale yüksek hızlı tren istasyon yerinin seçimi \\
{$[13]$} & AHP-MABAC & Hizlı tren projelerinin önceliklendirilmesi \\
{$[14]$} & AHP & Ankara-Sivas yüksek hızlı tren hat güzergâhının değerlendirilmesi \\
{$[15]$} & AHP & Monoray hat tipinin belirlenmesi \\
{$[16]$} & TOPSIS & Demiryolu konteyner hat terminalinin seçimi \\
{$[17]$} & AHP & Toplu taşıma türünün seçimi \\
\hline
\end{tabular}

Tablo 1'de yapılan çalışmalara bakıldığında yapılan çalışmaların istasyonların güzergâhlarının belirlenmesi ve yer seçimi yönünde olmuştur.

Demiryolu yolcu taşımacılığında, istasyon hizmetlerinin değerlendirilmesi için kriterlerin belirlenmesi aşamasında, uzman görüşleri ve literatür taramasında, Sharma, Roy ve diğerlerinin [2] çalışmasından yararlanılarak on ana kriter belirlenmiştir.

Temizlik (C1) : Demiryolu istasyonlarının temizlik kriteri [2] değerlendirildiğinde genel olarak bakıldığında istasyonda; bekleme salonları, peronlar, tuvaletler, istasyonun çevresi ve peyzajı açısından eksiksiz bir şekilde hijyenik, bakımlı ve göze hitap edecek şekilde olması demiryolu istasyonunun gelişmişlik düzeyini yükseltecek tren yolculuğunu daha cazip hale getirecek nitelikte bir kriterdir.

Güvenlik (C2) : İstasyonda yolcu ve yolcu bagajlarının elektronik sistemle kontrol edilebilmesi için, güvenliği sağlayacak personelin yeterli sayı ve uzmanlıkta olması gerekmektedir. Kamera sisteminin peronları, bekleme salonlarını ve tren yollarını açıkça görebilecek şekilde kurulmuş olması ve yeterli sayıda olması bir istasyonun güvenli olması açısından var olması gereken faktörlerdir.

Bekleme salonu (C3) : Yolcuların tren saatine kadar istasyonda güvenli ve eğlenceli zaman geçirmesi açısından istasyonun sağlaması gereken hizmet kalemidir. Oturma alanlarının yeterli ve konforlu olması, kapalı alanların 1sıtma ve soğutma sistemlerinin yeterli düzeyde olması temel etkenleri oluşturmaktadır. Televizyon, wi-fi olanağı, elektronik cihazlar için priz ve şarj cihazı alternatiflerinin var olması bekleme salonlarının cazibesini artırmaktadır. Tren iniş-biniş ve saatlerinin gösterildiği elektronik ekranların bulunması ve bilgilendirme amaçlı yapılan anonsların duyulmasını sağlayan ses sisteminin olması bir istasyonun sağlaması gereken hizmetler arasındadır.

Gişe hizmeti (C4) : İstasyon yönetimi yolcuların bilet, rezervasyon işlemlerinin hızlı bir şekilde yürütülmesi için kullanışlı ve pratik gişe sisteminin yanında yeterli personele de sahip olmak zorundadır. Personelin güleryüzlü, donanımlı olması ve satın alınan biletler hakkında yolcunun bilgilendirilmesi gerekmektedir. İstasyona gelen veya giden trenler hakkında hatırlatıcı anonslar yapılması, yolcuların hangi peronda beklemesi gerektiği konusunda uyarı yapılması ile beraber yolcu iniş-biniş sirkülasyonu takip edilmelidir. Yolcuların bagajlarını emanete vermek istemeleri 


\section{Demiryolu Mühendisliği}

durumunda yolcularla ilgilenmek tren istasyonlarında gişe hizmetleri görevleri arasında yer almaktadir.

Perona ulaşım kolaylığ 1 (C5) : İstasyonun yapı olarak büyük olduğu ve bağlantı olanaklarının yüksek olduğu istasyonlarda peronlar arası geçişi rahat ve emniyetli bir şekilde sağlamak açısından önemlidir. Yürüyen merdivenler sayesinde yolcuların bagajlarını taşımak açısından da kolaylık yaşayacağı bir kriterdir. Ayrıca fazla oranda yürüyen merdivene sahip olan istasyonun gelişmişlik seviyesi de üst düzeyde olduğunun bir göstergesidir.

Yeme-içme hizmeti (C6) : İstasyonda yeme-içme hizmetinin sunulması o istasyona ayrıcalık katacak bir kriterdir. Yeme-içme hizmetlerine ayrılan alanın genişliği, verilen hizmetin yolcuların tercih yapabileceği oranda sunduğu çeşitlilik ve peronlara yakın olması dolayısıyla yolcunun bu hizmete hızlı bir şekilde ulaşması istasyonun hizmet düzeyini arttıracak özelliklerdir. $\mathrm{Bu}$ hizmetlerin hepsi demiryolu standartlarına uygun olmak durumundadır [2].

Taşıyıcılar (C7) : İstasyonlarda nadir denebilecek kadar az sunulan, demiryolu istasyonlarının aralarında kıyaslandığında farklılığını ortaya koyabilecek nitelikte bir hizmettir. Fazla sayıda ya da ağır bagajların taşınması için istasyon yönetimi yolculara taşıyıcı hizmeti vermektedir [2]. Taşıyıcılar gerektiğinde engelli yolcuların trene binmesini kolaylaştıran aparatların trene yerleştirilmesi konusunda da hizmet vermektedirler.

Proaktiflik (C8) : Proaktiflik herhangi bir durum ya da olay karşısında muhatap bulabilmek ve hızlı bir şekilde probleme çözüm bulunması açısından muhatabın mevcut koşulların seyrini değiştirerek inisiyatif almasıdır [2]. Bir diğer değişle bir durumun tren istasyonu yetkilisi tarafından kontrol etmek amaciyla aldığı kararlar ile kriz yönetimidir. Örneğin yolcuların treni kaçırması, bagajını kaybetmesi, gişe hizmetlerinde oluşacak sorunları çözüme ulaştıracak kişiye ulaşabile durumu ve bu kişinin kısa sürede sorunu çözmesi istasyonu her açıdan olumlu seviyeye taşır.

Bağlantı olanakları (C9): Demiryolu istasyonunun gelişmişlik düzeyini belirleyen en önemli kriter istasyonun sahip olduğu bağlantı olanaklarıdır [2]. Demiryolu istasyonunun çok geniş bir hatta sahip olması, yollarının sayısının fazla olması, elektrikli hatlarının olması ve sinyalizasyon sisteminin olması bağlantı olanaklarının çok donanımlı bir sisteme sahip olduğunun göstergesidir. Genel olarak demiryolu hatlarının fazla gelişmemesi istasyonların diğer şehirlere olan bağlantısını kısıtlamış durumdadır.

Merkeze yakınlık (C10) : Merkeze yakınlık kriteri günümüzde insanların önem verdiği ulaşım açısından önemli bir seçenektir. İstasyonun konumunun merkezi olması yolcuların ulaşımını kolaylaştıran bir unsurdur. Merkeze yakın olan istasyonlar gelişim açısından merkeze uyum sağlamak zorunda oldukları için istasyon genelinin bakımlı ve temiz olma zorunluluğu doğar. İstasyonun merkeze yakın olmasının bir diğer avantajı insanların bekleme sürelerinde yakın yerleri gezip, ziyaret etme olanağı sunmaktadır.

Türkiye'de sık kullanılan yolcu istasyonları ele alınmış ve beş alternatif istasyon; Ankara, İstanbul (Pendik), Eskişehir, Kütahya ve Kocaeli (Gebze) olarak hizmet değerlendirmesi yapılmak üzere belirlenmiştir. 


\section{Demiryolu Mühendisliği}

\section{Bulgular}

Demiryolu istasyon hizmet değerlendirmesinde, Analitik Hiyerarşi Sürecine göre uygulama adımları Şekil 1'de görüldüğü gibidir.

\begin{tabular}{|c|}
\hline Demiryolu İstasyon Değerlendirme Probleminin Tanımlanması \\
\hline Demiryolu İstasyon Kriter ve Alternatiflerinin Hiyerarşik Yapısının \\
Oluşturulması \\
\hline Demiryolu İstasyon Değerlendirmesi İkili Karşılaştırma Matrislerinin \\
Oluşturulması \\
\hline Demiryolu İstasyon Değerlendirmesi için Kriterlerin Ağırlıklarının Belirlenmesi \\
\hline Tutarlılık Oranının Ölçülmesi \\
\hline Demiryolu İstasyon Değerlendirme Alternatiflerinin Sıralamasının Belirlenmesi \\
\hline Demiryolu İstasyon Değerlendirmesinin Gerçekleştirilmesi
\end{tabular}

Şekil 1. Analitik hiyerarşi süreci uygulama adımları

Yöntemin uygulama adımlarından ikincisini oluşturan, kriterler ve alternatifler arasındaki hiyerarşik yapı Şekil 2'de verilmiştir.

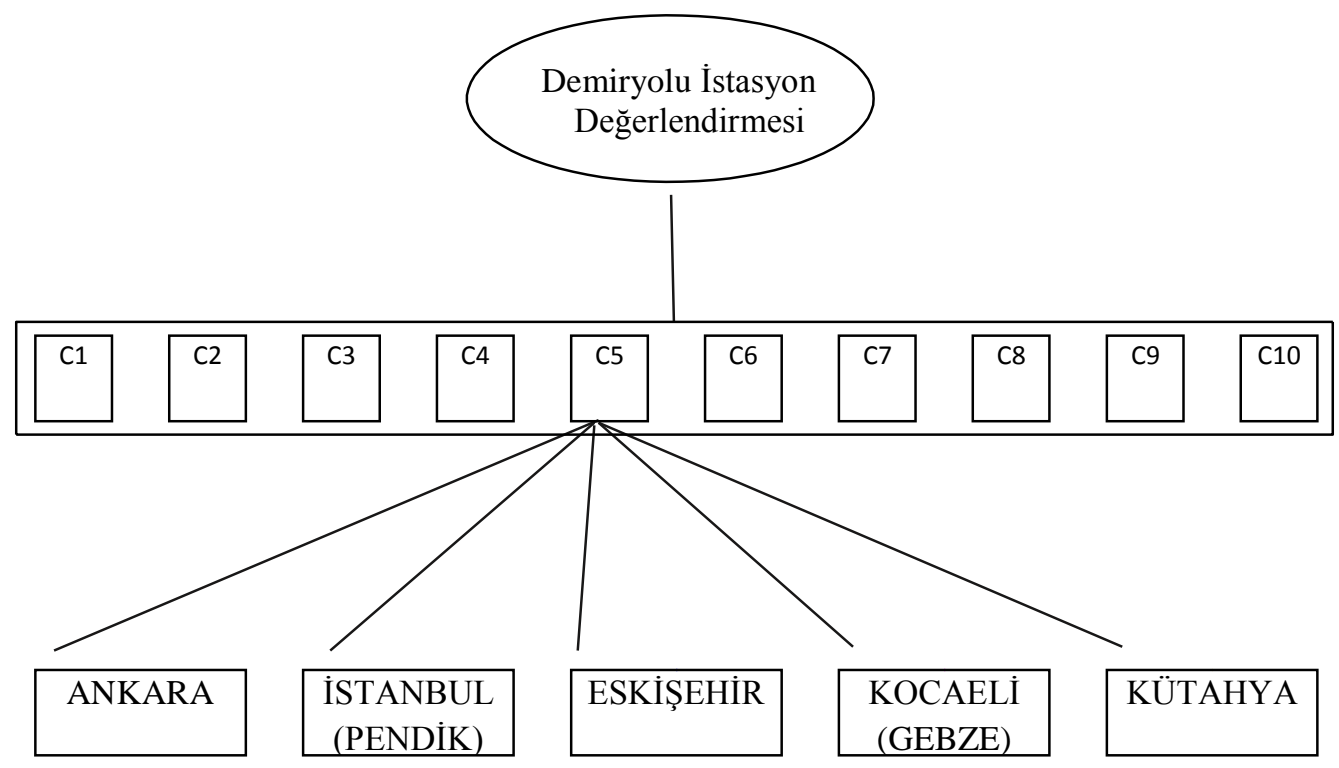

Şekil 2. Kriterler ve alternatifler arasındaki hiyerarşik yapı

İstasyonların sunduğu hizmetlerin değerlendirmesinde, probleminin değerlendirilmesi aşamasında, yolcu taşımacılığında sık kullanılan 5 istasyon belirlenmiş ve 10 kriter eşliğinde, Saaty'nin 1-9 puanlama ölçeğiyle değerlendirilmiş ve önem değerlerine göre birbirleri ile tek tek karşılaştırılmıştır. Uzmanların ortak görüşlerine dayanılarak, önem derecelerine göre puanlama yapılmış olan kriterler,

$$
a_{j i}=\frac{1}{a_{i j}}
$$

formülü uygulanarak ikili karşılaştırma matrisi tablosu Tablo 2'deki gibi oluşturulmuştur. 


\section{Demiryolu Mühendisliği}

Tablo 2. İkili matrislerin karşılaştırılması

\begin{tabular}{lllllllllll}
\hline & $\mathrm{C} 1$ & $\mathrm{C} 2$ & $\mathrm{C} 3$ & $\mathrm{C} 4$ & $\mathrm{C} 5$ & $\mathrm{C} 6$ & $\mathrm{C} 7$ & $\mathrm{C} 8$ & $\mathrm{C} 9$ & $\mathrm{C} 10$ \\
\hline $\mathrm{C} 1$ & 1,000 & 0,333 & 3,000 & 1,000 & 3,000 & 1,000 & 3,000 & 1,000 & 1,000 & 0,333 \\
$\mathrm{C} 2$ & 3,000 & 1,000 & 5,000 & 3,000 & 5,000 & 5,000 & 5,000 & 3,000 & 5,000 & 3,000 \\
$\mathrm{C} 3$ & 0,333 & 0,200 & 1,000 & 0,333 & 3,000 & 1,000 & 3,000 & 0,333 & 0,333 & 0,333 \\
$\mathrm{C} 4$ & 1,000 & 0,333 & 3,000 & 1,000 & 3,000 & 1,000 & 3,000 & 0,333 & 3,000 & 1,000 \\
$\mathrm{C} 5$ & 0,333 & 0,200 & 0,333 & 0,333 & 1,000 & 0,200 & 1,000 & 0,143 & 0,333 & 0,143 \\
$\mathrm{C} 6$ & 1,000 & 0,200 & 1,000 & 1,000 & 5,000 & 1,000 & 5,000 & 0,200 & 3,000 & 1,000 \\
$\mathrm{C} 7$ & 0,333 & 0,200 & 0,333 & 0,333 & 1,000 & 0,200 & 1,000 & 0,111 & 0,200 & 0,143 \\
$\mathrm{C} 8$ & 1,000 & 0,333 & 3,000 & 3,000 & 7,000 & 5,000 & 9,000 & 1,000 & 7,000 & 5,000 \\
$\mathrm{C} 9$ & 1,000 & 0,200 & 3,000 & 0,333 & 3,000 & 0,333 & 5,000 & 0,143 & 1,000 & 0,333 \\
$\mathrm{C} 10$ & 3,000 & 0,333 & 3,000 & 1,000 & 7,000 & 1,000 & 7,000 & 0,200 & 3,000 & 1,000 \\
$\mathrm{TOP}$ & 11,999 & 3,332 & 22,666 & 11,332 & 38,000 & 15,733 & 42,000 & 6,463 & 23,866 & 12,285 \\
\hline
\end{tabular}

Tablo 3. Demiryolu istasyon seçimi kriterlerinin ağırlıklarının belirlenmesi

\begin{tabular}{cccccccccccc}
\hline & $\mathrm{C} 1$ & $\mathrm{C} 2$ & $\mathrm{C} 3$ & $\mathrm{C} 4$ & $\mathrm{C} 5$ & C6 & C7 & C8 & C9 & C10 & Ağrlk \\
\hline C1 & 0,083 & 0,100 & 0,132 & 0,088 & 0,079 & 0,064 & 0,071 & 0,155 & 0,042 & 0,027 & 0,084 \\
C2 & 0,250 & 0,300 & 0,221 & 0,265 & 0,132 & 0,318 & 0,119 & 0,464 & 0,210 & 0,244 & 0,252 \\
C3 & 0,028 & 0,060 & 0,044 & 0,029 & 0,079 & 0,064 & 0,071 & 0,052 & 0,014 & 0,027 & 0,047 \\
C4 & 0,083 & 0,100 & 0,132 & 0,088 & 0,079 & 0,064 & 0,071 & 0,052 & 0,126 & 0,081 & 0,088 \\
C5 & 0,028 & 0,060 & 0,015 & 0,029 & 0,026 & 0,013 & 0,024 & 0,022 & 0,014 & 0,012 & 0,024 \\
C6 & 0,083 & 0,060 & 0,044 & 0,088 & 0,132 & 0,064 & 0,119 & 0,031 & 0,126 & 0,081 & 0,083 \\
C7 & 0,028 & 0,060 & 0,015 & 0,029 & 0,026 & 0,013 & 0,024 & 0,017 & 0,008 & 0,012 & 0,023 \\
C8 & 0,083 & 0,100 & 0,132 & 0,265 & 0,184 & 0,318 & 0,214 & 0,155 & 0,293 & 0,407 & 0,215 \\
C9 & 0,083 & 0,060 & 0,132 & 0,029 & 0,079 & 0,021 & 0,119 & 0,022 & 0,042 & 0,027 & 0,062 \\
C10 & 0,250 & 0,100 & 0,132 & 0,088 & 0,184 & 0,064 & 0,167 & 0,031 & 0,126 & 0,081 & 0,122 \\
\hline
\end{tabular}

Tablo 3.'ten elde edilen sonuçlara göre ikili karşılaştırma kriterlerinin ağırlıkları değerlendirilmiştir. İstasyonların birbirlerine göre sundukları hizmetlerin değerlendirilmesi için verilen kriterlerin önem sıralaması; ilk sırada bulunan "Güvenlik" kriteri (0.252) değeri ile en önemli kriter olarak belirlenmiştir. Daha sonra bunu takip eden "Proaktiflik" kriteri $(0,215)$ ise ikinci sırada yer alarak güvenlik kriterini takip etmiştir.

Saaty (1990)'ye göre tutarlıl1k oranı tutarlılık indeksinin (CI) rassal indekse (RI) bölünmesi ile elde edilmektedir. Rassal indeks Tablo 4'de gösterilmiştir. Tutarlılık göstergesi matris öz vektörünün alternatif sayısından ne kadar sapma olduğunu hesaplamaktadır.

Tablo 4. Rassal göstergeler

\begin{tabular}{cccccccccccccccc}
\hline $\mathrm{n}$ & 1 & 2 & 3 & 4 & 5 & 6 & 7 & 8 & 9 & 10 & 11 & 12 & 13 & 14 & 15 \\
\hline $\mathrm{RI}$ & 0 & 0 & 0,58 & 0,9 & 1,12 & 1,24 & 1,32 & 1,41 & 1,45 & 1,49 & 1,51 & 1,48 & 1,56 & 1,57 & 1,59 \\
\hline
\end{tabular}




\section{Demiryolu Mühendisliği}

Tutarlılık oranı; Kriterlerin ağırlık değerleri hesaplandıktan sonra kriterler önem derecelerine göre sıralanmıştır. Bu sıralamanın yani karar matrisinin tutarlı olup olmadığını kontrol etmek için tutarlılık oranına bakılması gerekmektedir. Bu test için kriterlerin ağırlıkları bulunduktan sonra ağırlık değerleri öz vektöre bölünmüştür ve tutarlılık oranı;

$$
\begin{array}{r}
\lambda=\frac{\sum_{i=1}^{n} E_{i}}{n} \\
C I=\frac{\lambda-n}{n-1} \\
C R=\frac{C I}{R I}
\end{array}
$$

Öncelikle CI tutarlılık göstergesini elde edebilmek için (2) formülü kullanılarak $\lambda$ vektörü değeri 11.12557 elde edilmiştir. İkinci aşamada CI değerini bulabilmek için (3) formülüne göre hesaplanan tutarlılık göstergesinin değeri 0,125063 olarak bulunmuştur. Ve CR tutarlılık oranı için (4) formülünden yararlanılarak bu oranın değeri 0,083935 olarak hesaplanıştır.

İkili karşılaştırma matrisi oluşturulurken verilen değerlerin ilişkisinin tutarlı olması için tutarlılık oranı $\mathrm{CR}<0,10$ olması gerekmektedir. Bulunan sonuçlardan elde edilen değer 0,083935 $<0,10$ 'dan daha düşük olduğu için matrislerin karşılaştırılması oranı tutarlıdır.

Alternatiflerin değerlendirilmesi sonucunda sütun vektörleri ve karar matrisi oluşturulur ve kriter karşılaştırmaları sonucu elde edilen sütun vektörü ile çarpılır. Elde edilen yeni sütun vektörünün her elemanı karar alternatiflerin değerlerini belirler ve toplamı bir olacak şekilde meydana gelen bu puanlarda en büyük puana sahip değer en uygun alternatif olarak seçilmektedir.

Tablo 5. Alternatiflerin normalize matrisi

\begin{tabular}{lcccccccccc}
\hline & C1 & C2 & C3 & C4 & C5 & C6 & C7 & C8 & C9 & C10 \\
\hline Ankara & 0,310 & 0,272 & 0,360 & 0,225 & 0,266 & 0,529 & 0,272 & 0,161 & 0,257 & 0,219 \\
İstanbul & 0,241 & 0,212 & 0,120 & 0,161 & 0,233 & 0,058 & 0,090 & 0,225 & 0,200 & 0,219 \\
Eskissehir & 0,172 & 0,212 & 0,280 & 0,290 & 0,300 & 0,294 & 0,454 & 0,225 & 0,257 & 0,219 \\
Kütahya & 0,103 & 0,090 & 0,200 & 0,161 & 0,033 & 0,058 & 0,090 & 0,225 & 0,142 & 0,170 \\
Kocaeli & 0,172 & 0,212 & 0,040 & 0,161 & 0,166 & 0,058 & 0,090 & 0,161 & 0,142 & 0,170 \\
TOPLAM & 1,000 & 1,000 & 1,000 & 1,000 & 1,000 & 1,000 & 1,000 & 1,000 & 1,000 & 1,000 \\
\hline
\end{tabular}

Tablo 6. İstasyon değerlendirmesi alternatiflerinin önem değerleri

\begin{tabular}{cc}
\hline Alternatifler & Önem Değerleri \\
\hline Ankara & 0,266 \\
İstanbul (Pendik) & 0,194 \\
Eskişehir & 0,240 \\
Kütahya & 0,141 \\
Kocaeli (Gebze) & 0,159 \\
\hline
\end{tabular}




\section{Demiryolu Mühendisliği}

Yapılan değerlendirmeler sonucunda; Ankara, 0,266; İstanbul (Pendik), 0,194; Eskişehir, 0,240; Kütahya, 0,141; Kocaeli (Gebze), 0,159 olarak hesaplanmıştır.

AHS yöntemi sonucunda; Tablo 6'ya göre Türkiye'deki demiryolu istasyonlarının değerlendirmesi sonucu bir sıralama elde edilmiştir. Birinci sırada Ankara $(0,266)$ istasyonu, ikinci sırada Eskişehir $(0,240)$ istasyonu, üçüncü sırada İstanbul (Pendik) $(0,194)$ istasyonu, dördüncü sırada Kocaeli (Gebze) $(0,159)$ istasyonu, beşinci sırada ise Kütahya $(0,141)$ istasyonu olarak yer almaktadır.

İlk sırada öne çıkan Ankara istasyonu, belirlenen kriterleri en üst düzeyde hizmet sunacak kadar yatırım yapılmış ve geliştirilmiş bir istasyon olarak birinci sırada yer almıştır. Ankara istasyonunda genel olarak yolcu sirkülasyonunun çok olduğu, güvenlik ve proaktiflik kriteri haricinde diğer kriterleri de önemli derece etkinleştirdiği görülebilir. Bu sonuçtan yola çıkılarak istasyonlara yapılan bu yatırımların, sunduğu hizmet olanaklarının ne derece önemli olduğunu ve demiryolu taşımacılığı hizmetlerini olumlu yönde etkileyeceğinin bir göstergesidir.

\section{Sonuç ve Yorum}

$\mathrm{Bu}$ çalışma, yolcu taşımacılığında istasyonların sunduğu hizmetleri değerlendirmek amacıyla yapılmış bir araştırmadır. Türkiye'de demiryolu istasyonlarının sahip olduğu olanaklar dâhilinde sunduğu hizmetlerin çeşitliliği göz önünde bulundurularak, hangi istasyonun hizmet düzeyinin daha üst seviyede olduğunu belirlemek amaçlanmıştır. İstasyonun sağladığı hizmetler, (temizlik, güvenlik, bekleme salonları, gişe hizmetleri, yürüyen merdivenler, yeme-içme hizmetleri, taşıyıcılar, proaktif olmak, bağlantı olanakları ve merkeze yakınlık gibi) kriterler ele alınarak, istasyonlar her hizmet için ayrı ayrı değerlendirilmiştir. İstasyonların kriterlerin önem derecelerine göre Türkiye'de alternatif olarak belirlenen demiryolu istasyonlarına yönelik bir hizmet değerlendirmesi gerçekleştirilmiştir.

Demiryolu istasyon hizmet değerlendirmesi yapılırken birden fazla objektif ve sübjektif kriterin analizi için ve alternatifleri değerlendirmek üzere çok kriterli karar verme yöntemlerinden Analitik Hiyerarşi Süreci (AHS)'nden yararlanılmıştır. Türkiye'de sık kullanılan 5 demiryolu istasyonu (Ankara, İstanbul (Pendik), Eskişehir, Kütahya, Kocaeli (Gebze)) olarak ele alınmıştır. Uzman görüşlei ve literatür taramasından yararlanılarak 10 hizmet kriteri ( temizlik, güvenlik, bekleme salonu, gişe hizmeti, perona ulaşım kolaylığı, yeme-içme hizmeti, taşıyıcılar, proaktiflik, bağlantı olanakları, merkeze yakınlık) ile istasyonların birbirlerine göre hizmet değerlendirmeleri yapıldı. Kriter ve alternatiflerin ağırlık puanları AHS ile belirlenerek, hizmeti en iyi veren istasyon sıralaması elde edilmiştir. Öncelikle ikili karşılaştırma matrislerinden elde edilen kriterlerin ağırlıkları değerlendirildiğinde istasyonda verilen hizmetlerin önem sırası elde edilmiştir.

Bu sıralamaya göre; ilk sırada "Güvenlik' kriteri $(0,252)$, değeri ile istasyonlarda önem verilen en önemli kriter olarak belirlenmiştir. Sirasiyla "Proaktiflik'" kriteri $(0,215)$, "Merkeze yakınlık" kriteri $(0,122)$, "Gişe hizmeti", kriteri $(0,0889)$, “Temizlik" kriteri $(0,084)$, "Yeme-İçme hizmeti"'(0,083), "Bağlant olanaklarl" kriteri $(0,062)$, "Bekleme salon " kriteri $(0,047)$, “Perona ulaşım kolaylığı” kriteri $(0,024)$, “Taşıylcılar' kriteri $(0,023)$, değerlerini alarak önem dereceleri sıralanmıştır. Kriterleri en üst düzeyde karşılayan istasyon hizmet değerlendirmesi gerçekleştirilmiş ve alternatifler arasında "Ankara" $(0,931)$ değeri ile ilk sırada yer alan istasyon olarak belirlenmiştir. Diğer istasyonların kriterleri karşılama sıralaması şu şekildedir; ikinci sırada “Eskişehir"' $(0,743)$ istasyonu, üçüncü sirada "IIstanbul (Pendik)'" $(0,427)$ istasyonu, dördüncü sırada "Kocaeli (Gebze)" $(0,061)$ istasyonu, beşinci sırada ise "Kütahya" $(0,037)$ istasyonu takip ederek istasyonların birbirlerine göre hizmet sıralaması elde edilmiştir. 


\section{Demiryolu Mühendisliği}

Sonuç olarak bu çalışmada; Ankara istasyonunun belirlenen kriterler eşliğinde verdiği hizmetler bütününün diğer istasyonlara göre daha üstün olduğu belirlenmiştir. Özellikle önem derecesi yüksek olan "güvenlik" ve "proaktiflik" kriterlerini üst seviyede karşılayabildiği ortaya konulmuştur. Buna bağlı olarak sunduğu hizmet kalemlerinin düzeyi yüksek olduğu için yolcu taşımacılığını da olumlu etkilemektedir. İstasyonların donanımlı olması, teknolojik özelliklere sahip olmas1, yolcu potansiyelini demiryoluna çekebilecek etkenler olarak önem verilmesi gerektiğini ortaya koymuştur. Devlet tarafından demiryoluna yapılan yatırımlarında bu yönde değerlendirilmesi öngörülmektedir. İstasyonlara yapılan yatırımların yolcu taşımacılığında kar etme oranında etkisi büyüktür. $\mathrm{Bu}$ amaçla bütün istasyonlar kar etmek amaciyla var olan hizmetleri eşit derecede sunmalı ve yeni hizmet kalemleri için istasyonlara yatırım yapılmalıdır. Bu çalışmada kullanılan hizmet kriterlerinin gelecekte yapılacak çalışmalara alt yapı oluşturması ve yardımcı olması amaçlanmıştır. Yapılacak yeni çalışmalar ile farklı değerlendirme kriterleri belirlenerek, istasyonların performansları arttırılabilir ve yolcu taşımacılığını daha çok geliştirebilir.

\section{Kaynakça}

[1] E. Gerede, Havayolu taşımacllığ ve ekonomik düzenlemeler teori ve Türkiye uygulaması. Sivil Havacılık Genel Müdürlüğü, Eskişehir, Basım, (ed). 2015.

[2] H. K. Sharma, J. Roy, S. Kar ve O. Prentkovskis, "Multı criterıa evaluation framework for prioritizing indian ralway stations using modified rough ahp-mabac method". Transport and Telecommunication, vol.19, no. 2, pp. 113-127, Ocak 2018.

[3] M. Givoni and P. Rietveld, "The access journey to the railway station and its role in passenger satisfaction with rail travel," Transport Policy vol.14, pp. 357-365. 2007.

[4] V. Engin, A. Uçar ve O. Doğan, Osmanlı'da Ulaşım Kara-Deniz-Demiryolu. İstanbul, Çamlıca Basım, (ed.). 2012.

[5] T. L. Saaty, Theory and applications of the analytic network process:decision making with benefits, opportunities, costs, and risks. RWS Publications, USA., 2005.

[6] H.Gerçek, B. Karpak, ve T. Kılınçaslan, "A multiple criteria approach for the evaluation of the rail transit networks in istanbul," Transportation vol. 31, pp. 203-228, Mayıs 2004.

[7] A. Djenaliev,"Multicriteria decision making and gis for railroad planning in kyrgyzstan," School of Architecture and The Built Environment Royal Institute of Technology, Stockholm, Sweden,2007.

[8] N. Mohajeri, ve G. Amin, "Railway station site selection using analytical hierarchy process and data envelopment analysis," Computers \& Industrial Engineering, vol. 59, no. 1, pp. 107-114, Ağustos 2010.

[9] Y. Esmizadeh ve M. Bashiri, "Hub location selection decision with a hybrid method of fuzzy dematel analytical network process and fuzzy vikor," 6th International Conference Of Iranian Operations Research Society, pp. 1-2, Tehran,Iran, 8-9 May1s 2013.

[10] S. Chen, Y.Leng, B. Mao ve S. Liu, "Integrated weight-based multi-criteria evaluation on transfer in large transport terminals a case study of the beijing south railway station," Transportation Research Part A Policy and Practice, vol. 66, no. 1, pp. 13-26,Ağustos 2014.

[11]O. Kılıç ve H. Çerçioğlu, "Tcdd iltisak hatları projelerinin değerlendirilmesinde uzlaşık çok ölçütlü karar verme yöntemleri uygulaması," Gazi Üniversitesi Mühendislik ve Mimarlık Fakültesi Dergisi, vol. 31, no. 1, pp. 211-220, Aralık 2016.

[12]T. Eren, E. Hamurcu ve M. Alağaş, "Çok kriterli karar verme yöntemleri ile kırıkkale yüksek hızlı tren istasyon yerinin seçimi," 5. Uluslararası Mühendislik ve Bilimde Yenilikçi Teknolojiler Seтровуити, pp. 598-606, Bakü-Azerbaycan, 29-30 Eylül, 2017.

[13]E. Hamurcu, ve T. Eren, "Prioritization of high-speed rail projects," International Advanced Researches and Engineering Journal, vol. 02, no. 02, pp. 098-103, Ağustos 2018.

[14] İ.N. Süt, M. Hamurcu ve T. Eren, "Analitik hiyerarşi süreci kullanılarak ankara-sivas yüksek hızlı tren hat güzergâhının değerlendirilmesi,"Harran Üniversitesi Mühendislik Dergisi, vol.3, no. 3, pp. 22-30, Aralik 2018.

[15] M. Taş, N. Ş. Özlemiş, M. Hamurcu, ve T. Eren, “Ankara'da ahp ve promethee yaklaşımıyla monoray hat tipinin belirlenmesi," JEBPIR Dergisi, vol.3 no. 1, pp. 65-89, Haziran 2017. 


\title{
Demiryolu Mühendisliği
}

[16] M. Milosavljević, M.Bursac ve G. Tričković, "Selectıon of the ra1lroad contaıner terminal in serbia based on multı criteria decision-makıng methods," Applications in Management and Engineering, vol. 1, no. 2, pp. 1-15, Mayis 2018.

[17] M. Hamurcu ve T. Eren, "Toplu taşıma türünün seçiminde çok kriterli karar verme uygulaması," International Conference on Advenced Engineering Tecnonologies-ICADET'17, pp. 1-18, , Bayburt, 21-23 Eylül, 2017.

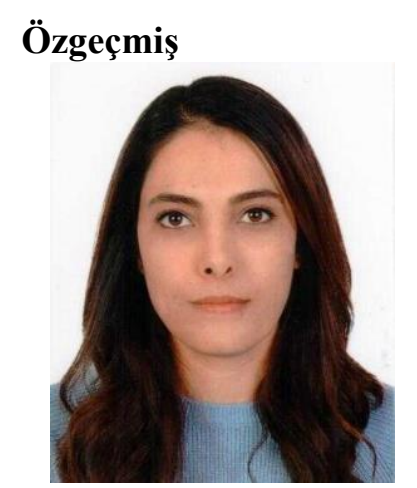

\author{
Sinem KAYA \\ 1990 tarihinde doğmuştur. Lisans eğitimini Gaziantep \\ Üniversitesinde, yüksek lisans eğitimini Akdeniz Üniversitesinde \\ tamamlamıştır. TCDD Taşımacılık A.Ş. Genel Müdürlüğü Yük \\ Dairesi Başkanlığı, Uluslararası Taşımalar Şubesinde çalışmaktadır. \\ E-Posta: kayasinem@hotmail.com.tr
}

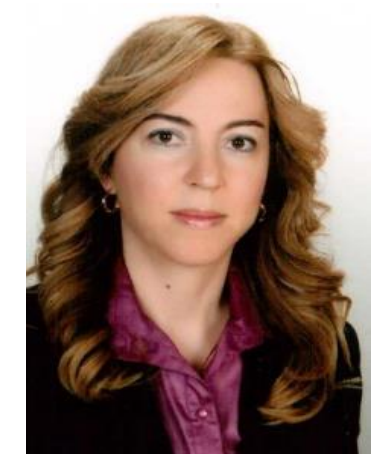

\section{Fahriye MERDİENCI}

1968 tarihinde doğmuştur. Lisans eğitimini Dokuz Eylül Üniversitesinde, yüksek lisans ve doktora eğitimini Akdeniz Üniversitesinde tamamlamıştır. Akdeniz Üniversitesi Uygulamalı Bilimler Fakültesinde çalışmaktadır.

E-Posta: fahriye@akdeniz.edu.tr

\section{Beyanlar}

Bu makalede bilimsel araştırma ve yayın etiğine uyulmuştur.

Tüm yazarların eşit oranda katkısı olmuştur. 